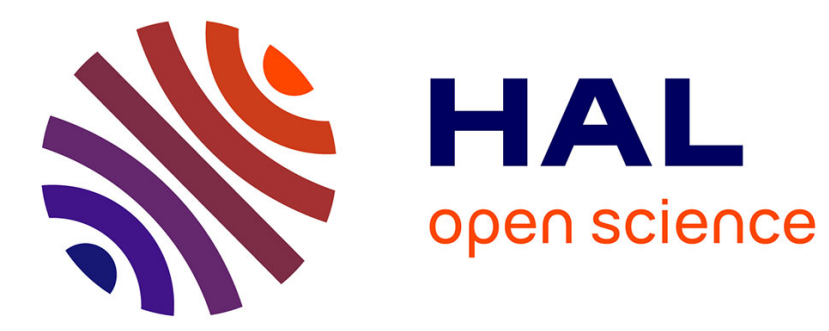

\title{
Time knowledge difficulties following treatment for malignant cerebellar tumors
}

Florence Labrell, Hugo Câmara-Costa, Virginie Kieffer, Georges Dellatolas

\section{To cite this version:}

Florence Labrell, Hugo Câmara-Costa, Virginie Kieffer, Georges Dellatolas. Time knowledge difficulties following treatment for malignant cerebellar tumors. Child Neuropsychology, 2018, 24 (4), pp.524-540. 10.1080/09297049.2017.1296122 . hal-02566740

\section{HAL Id: hal-02566740 \\ https://hal.science/hal-02566740}

Submitted on 7 May 2020

HAL is a multi-disciplinary open access archive for the deposit and dissemination of scientific research documents, whether they are published or not. The documents may come from teaching and research institutions in France or abroad, or from public or private research centers.
L'archive ouverte pluridisciplinaire HAL, est destinée au dépôt et à la diffusion de documents scientifiques de niveau recherche, publiés ou non, émanant des établissements d'enseignement et de recherche français ou étrangers, des laboratoires publics ou privés. 


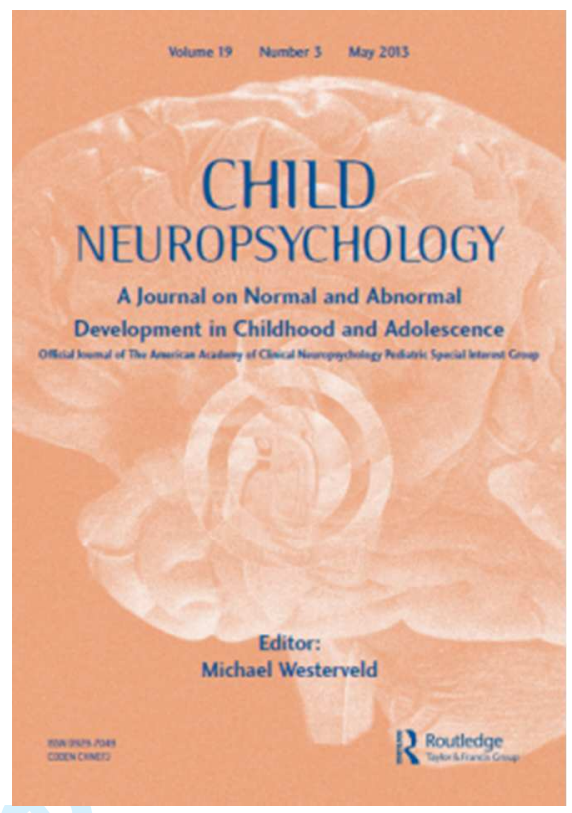

\section{Time knowledge difficulties in children treated for medulloblastoma}

\begin{tabular}{|r|l|}
\hline Journal: & Child Neuropsychology \\
\hline Manuscript ID & Draft \\
\hline Manuscript Type: & Original Article \\
\hline Date Submitted by the Author: & n/a \\
\hline Complete List of Authors: & $\begin{array}{l}\text { Labrell, Florence; Centre de recherche en Epidemiologie et Sante des } \\
\text { Populations } \\
\text { Câmara Costa, Hugo; Centre de recherche en Epidemiologie et Sante des } \\
\text { Populations } \\
\text { Kieffer, Virginie; Gustave Roussy } \\
\text { Dellatolas, Georges; Centre de recherche en Epidemiologie et Sante des } \\
\text { Populations }\end{array}$ \\
\hline Keywords: & $\begin{array}{l}\text { time processing, action-perception coupling, number, medulloblastoma, } \\
\text { child }\end{array}$ \\
\hline &
\end{tabular}

SCHOLARONE ${ }^{\text {m }}$

Manuscripts 
TIME KNOWLEDGE IN MEDULLOBLASTOMA

1

2

3

4

5

6

7

8

9

10

11

12

13

14

15

16

17

18

19

20

21

22

23

24

25

26

27

28

29

30

31

32

33

34

35

36

37

38

39

40

41

42

43

44

45

46

47

48

49

50

51

52

53

54

55

56

57

58

59

60

\section{Time knowledge difficulties in children treated for medulloblastoma}

Florence Labrell $^{1,2,}$, Hugo Câmara-Costa ${ }^{1}$, Virginie Kieffer ${ }^{3,4}$, Georges Dellatolas ${ }^{1}$

${ }^{1}$ Université Paris-Saclay, université Paris-Sud, UVSQ, CESP, Inserm, Villejuif, France

${ }^{2}$ INSHEA (national institute for training and research on special education), Suresnes, France

${ }^{3}$ Hôpitaux de Saint Maurice, Saint Maurice; Groupe de Recherche Clinique Handicap Cognitif et Réadaptation; UPMC Paris 6, France

${ }^{4}$ Gustave Roussy, Villejuif 94805, France

${ }^{\dagger}$ Corresponding author: Florence Labrell, CESP INSERM U1018, 16, avenue Paul Vaillant Couturier, 94807 Villejuif, France. Tel: (+33) (0)1 455952 48; E-mail: florence.labrell@gmail.com

Running title: Time knowledge in medulloblastoma

Funding: This research did not receive any specific grant from funding agencies in the public, commercial, or not-for-profit sectors.

\section{Conflict of interest: none}


TIME KNOWLEDGE IN MEDULLOBLASTOMA

\begin{abstract}
In children treated for malignant cerebellar tumors (MCT), there are only a few studies investigating temporal skills, despite a generally admitted role of the cerebellum in time processing. Children's Time Knowledge (TK) has been defined as the correct representation and use of familiar time units (Labrell, Mikaeloff, Perdry, \& Dellatolas, 2016).

The present study compares TK in 38 children treated for MCT (mean age 11.6 years) with 105 typically-developing children (TDC).

Performances on all TK subtests were significantly lower in the MCT group. The results also confirmed lower mean IQ in children treated for MCT, related to slow processing speed and low performance on working memory and non-verbal tasks. However, low IQ did not explain the considerable difficulties in the acquisition of TK.

These results are discussed in the light of the role of the cerebellum in time processing and two different models of temporal processing, the internal clock model (Allman, Teki, Griffiths, \& Meck, 2014) and the neural network state model (Karmarkar \& Buonomano, 2007).
\end{abstract}

Keywords: Time-processing, action-perception coupling, number, medulloblastoma, child. 
TIME KNOWLEDGE IN MEDULLOBLASTOMA

\section{Introduction}

In typically developing children, there are numerous studies and theories exploring the development of temporal perception and temporal thinking. In children treated for medulloblastoma, a malignant tumor of the cerebellum, there are only a few studies investigating temporal skills, despite a generally admitted role of the cerebellum in time processing.

\subsection{Time-related investigations in typically developing children}

How do children acquire a mature conception of time? According to a recent account (McCormack, 2014), very young children have a script-based, event-dependent temporal perspective, based on representations of repeated event sequences, such as bedtime routines, being able to accurately order the events in these sequences (e.g. story time comes after brushing the teeth). Around 3 years, children are able to make a categorical distinction between events that have already happened (i.e. past "unalterable" events), and events that have yet to happen (i.e. future potentially "alterable" events). A mature event-independent temporal perspective based on a linear temporal framework (from age 5-6 years) requires hypothetical thinking about the past and the future, possibly related to the capacity for "mental time travel" (Tulving, 2002). For instance, if A, B, and C are successive past events, when B occurred, A was in the past and $\mathrm{C}$ in the future.

The development of time perception during childhood has been investigated for short time intervals (from sub-seconds to a few seconds) with tasks of temporal reproduction, temporal generalization or temporal discrimination, under the "internal clock" model of temporal processing (Allman, Teki, Griffiths, \& Meck, 2014; Gibbon, Church, \& Meck, 1984). These tasks do not use any verbal coding of time (i.e. numbers and time units), and are difficult to apply to long durations (e.g. hours). They show improvement in time sensitivity during childhood, associated with an improvement in other cognitive functions such as attention, working memory or processing speed (Droit-Volet, 2013). These tasks are clearly different from time-related tasks using conventional time units in their instructions, such as time production tasks (e.g. producing a duration of a number of seconds) or in their required answers (i.e. giving a verbal estimation of the duration using numbers and time units). These are based on the correct mental representation of the duration of a given time unit (e.g. how long is one second, 
TIME KNOWLEDGE IN MEDULLOBLASTOMA

one minute, one hour, etc) and can be considered as "cognitive estimation" tasks (Shallice \& Evans, 1978).

In Friedman's work with children from preschool to late adolescence, the use of conventional time units with longer durations (e.g. days, weeks, months) was partially investigated. For instance, to "how long" questions (e.g. how long is it until your next birthday?), responses in conventional units (e.g. a number of days, weeks, or months) were rare and very inaccurate in 4-year-olds, not systematic and with variable accuracy in 7-year-olds, and systematic and generally accurate in 10-year-olds (Friedman, 2000). In another series of experiments exploring the representation of the days of the week and the months of the year, from second grade to college, Friedman proposed a 2-stage model, where the younger subjects use a verbal-list-based representational processing system and the older subjects an additional "image system" based on temporal distances (Friedman, 1986).

In a previous report (Labrell, Mikaeloff, Perdry, \& Dellatolas, 2016), we defined Time Knowledge (TK) as the correct representation and use of familiar time units (i.e. from seconds to years). A Time Knowledge Questionnaire (TKQ) was proposed for the evaluation of TK in elementary school children (6 to 11 years). The TKQ assesses conventional time knowledge (temporal orientation, temporal sequences, relationships between time units, and telling the time on a clock), estimation of longer durations (months, years) related to life span or birthday, and estimation of the duration of the interview. All the items in the TKQ involve time units, and consequently numbers. In typically developing children, TK increased dramatically with age, especially between 6 and 8 years, and correlated strongly with the acquisition of numerical skills and working memory. In older children, a numerical cognitive estimation task (e.g. the number 10 is few for "leaves on a tree, but many for "children in a family"), was the only numerical factor associated with TK. Another tool previously proposed for the assessment of time-processing abilities in non-typically developing children (Janeslätt, Kottorp, \& Almqvist, 2010) also contains many “cognitive estimation” questions, such as saying which of two proposed activities takes a shorter time, or saying which activity can be completed in a given time.

\subsection{Processing time and the cerebellum}


There is strong evidence of the role of the cerebellum in cognition (Schmahmann \& Sherman, 1998) and also continuing debate about the description and understanding of the cerebellar functions (Baumann et al., 2015; Koziol et al., 2014). Some authors suggest that the cerebellum contributes to cognitive processing when temporal demands are critical (De Zeeuw \& Ten Brinke, 2015; Rahmati et al., 2014). For instance, De Zeeuw and Ten Brinke (2015), after describing the mechanisms of motor learning in the cerebellum, specifically the adaptation of the vestibulo-ocular reflex and eye blink conditioning, concluded that the most characteristic feature among all the functions of the cerebellum is its ability to control timing at a high resolution, and suggested that this cerebellar temporal function might be also critical in complex timing-sensitive processes involved in cognition and episodic memory. According to a recent review (Baumann et al., 2015), there is general consensus that cerebellar contributions to timing are more pronounced with relatively short intervals (under $1 \mathrm{~s}$ ), such as those involved, for instance, in eye blink conditioning, interception of a moving object, velocity perception or temporal prediction violations. Impressive evidence for the role of the cerebellum in sub-second duration processing comes from a study reporting that a 4-day training in a temporal discrimination task in the millisecond range (around $200 \mathrm{~ms}$ ) induces structural changes in the right cerebellum in humans (Bueti, Lasaponara, Cercignani, \& Macaluso, 2012). Neuro-imaging studies exploring time processing suggest that sub-second timing tasks are processed in the motor system and recruit sub-cortical networks, such as the basal ganglia and the cerebellum, whereas suprasecond durations activate cortical structures and utilize attention capacity and working memory to keep track of time (Hayashi, Kantele, Walsh, Carlson, \& Kanai, 2014; Wiener, Turkeltaub, \& Coslett, 2010). However, there is also some evidence that the cerebellum is activated by temporal tasks involving suprasecond durations. For instance, in functional neuroimagery studies of "mental time travel" (Tulving, 2002), the cerebellum is activated when subjects vividly envision a personal future event (Szpunar, Watson, \& McDermott, 2007) or repeatedly imagine taking a short walk in a familiar environment, either in the past or in the future (Nyberg, Kim, Habib, Levine \& et Tulving, 2010).

\subsection{Time-related investigations in patients with cerebellar lesions}


TIME KNOWLEDGE IN MEDULLOBLASTOMA

In patients with cerebellar lesions, many investigations report time processing deficits, as well as the difficulty in separating "pure" time processing deficits from other motor or cognitive deficits induced by the lesion of the cerebellum (Keren-Happuch, Chen, Ho, \& Desmond, 2014). In a seminal study (Ivry \& Keele, 1989), 27 adults with various cerebellar pathologies (stroke, tumor, cerebellar degeneration) had difficulty maintaining a simple rhythm and discriminating between small differences in the duration of two intervals in the 160 to $640 \mathrm{~ms}$ range, whereas patients with other neurological deficits (Parkinson disease, cerebro-cortical or peripheral pathologies) did not show deficits in timing functions. More recently (Gooch, Wiener, Wencil, \& Coslett, 2010) eleven adults with cerebellar lesions (mainly stroke) were compared to 17 controls on temporal estimation, temporal production and temporal reproduction tasks, in the suprasecond range (2-12s). Patients with cerebellar damage showed significant impairments on these tasks, more pronounced for short intervals (near $2 \mathrm{~s}$ ) than for longer intervals (near $12 \mathrm{~s}$ ). The authors suggest a disruption of a left cerebellar-right frontal network implicated in working memory. The role of working memory in time reproduction has been also suggested by another study (Harrington, 2003), which compared perception and reproduction of short time intervals (under 1s) between 21 patients with cerebellar damage after stroke and 30 controls. The authors found impairments only in time reproduction and hypothesized that cerebellar damage could disrupt the maintenance of time intervals in working memory during time reproduction. Furthermore, evidence of an involvement of working memory in time reproduction of "short" time intervals (up to a few seconds) has been reported in other studies, showing, for instance, that the continuation phase of time reproduction (e.g. continuing tapping every $300 \mathrm{~ms}$ or every $600 \mathrm{~ms}$ ) activates a covert auditory-rehearsal network in the prefrontal cortex (Rao et al., 1997). Likewise, other investigations indicated selective deficits of verbal working memory in patients with cerebellar lesions (Ravizza et al., 2006), and provided evidence for a cerebellar contribution to verbal workingmemory in healthy subjects (Marvel \& Desmond, 2010). However, similar studies performed with children are scarce.

\subsection{Cognitive and time-related investigations in children treated for medulloblastoma}


Medulloblastoma is the most common malignant childhood central nervous system tumor, arising infratentorially in the cerebellum or the fourth ventricle. Treatment generally includes surgery, cranial radiotherapy and chemotherapy (Bartlett, Kortmann, \& Saran, 2013). Children treated for malignant cerebellar tumors (MCT), especially medulloblastoma, often present a Full Scale IQ (FSIQ) decline, at least in the first 7 years after the end of treatment (Grill et al., 1999; Palmer et al., 2001), possibly related to core cognitive deficits such as low processing speed and deficient attention and working memory (Mabbott, Penkman, Witol, Strother, \& Bouffet, 2008a; Palmer et al., 2013). FSIQ decline and core cognitive deficits have been associated with radiotherapy-induced white matter loss (Mulhern et al., 1999), and also with the tumor- and surgery-induced cerebellar damage (Grill et al., 2004; Puget et al., 2009).

Proposed core cerebellum-dependent cognitive deficits, possibly explaining the FSIQ decline in children treated for cerebellar tumors, (see Chevignard, Câmara-Costa, Doz, \& Dellatolas, 2016, for a recent review), include deficits in sequence learning (Leggio et al., 2008), verbal working memory (Ravizza et al., 2006), attention (Palmer et al., 2013), executive function (Koustenis, Hernáiz Driever, de Sonneveille, \& Rueckriegel, 2016; Law et al., 2015), and processing speed (Mabbott, Penkman, Witol, Strother, \& Bouffet, 2008b; Palmer et al., 2013; Wolfe, Madan-Swain, \& Kana, 2012). At least some of these deficits may be related to a specific role of the cerebellum in motor and cognitive learning through the establishment of automatisms after repeated execution of the same motor or cognitive task (Ramnani, 2014). A cerebellar injury-induced automation deficit could account for a lower processing speed and excessive demands on attention (Ait Khelifa-Gallois et al., 2015).

In a study with subjects aged 11-36 years treated for medulloblastoma or benign cerebellar tumors (astrocytomas), short (in the 400-ms range) and long (30-60 min) duration perception was investigated, as well as estimation of the time needed to walk 20 meters, before and after actual performance of this walk (Hetherington, Dennis, \& Spiegler, 2000). The tumor group showed deficits in short duration perception compared to the controls, whereas long-duration estimation was overall spared. However, the medulloblastoma group overestimated retrospectively the time actually required to walk 20 meters (e.g. answer $36 \mathrm{~s}$, actual $17 \mathrm{~s}$ ) and there was no correlation in this group between actual time and retrospective estimation. The authors concluded that the medulloblastoma group had 
TIME KNOWLEDGE IN MEDULLOBLASTOMA

difficulty refining real-world spatiotemporal estimates with sensory and somatomotor information. This seems in accordance with another recent investigation using a virtual-reality paradigm, reporting that, compared to healthy controls, cerebellar patients showed no beneficial influence of action execution on perception (Christensen et al., 2014).

Children treated for medulloblastoma, showed preserved temporal discrimination for durations between 0.5 and 8 seconds, but difficulty reproducing short intervals ( 0.5 to 1 second), associated with low processing speed (Droit-Volet, 2013). Another study in the same patients, exploring rhythm perception and production, showed intact rhythm discrimination but slow and variable spontaneous motor tempo and disrupted sensorimotor synchronization (Provasi et al., 2014). "Conceptions of time" were compared between 20 children treated for malignant cerebellar tumors, mainly medulloblastoma, aged 6-12 years, and 20 controls, using multiple choice questions on the duration of daily activities (e.g. brushing your teeth for 30 minutes, is it long, short, or average?), planning (e.g. if you have 5 minutes left, is it possible to eat a sandwich?), and "time units" (e.g. during the night you are likely to sleep 4 hours, 18 hours, or 10 hours?) (Labrell, Kieffer, Grill, \& Dellatolas, 2014). The tumor group showed more difficulty correctly judging the duration of daily activities. All these questions are cognitive estimate questions.

However, cognitive estimation is not about time exclusively (Bullard, 2004). A recent version of the cognitive estimation task (MacPherson et al., 2014), initially proposed by Shallice and Evans (1978), favored the "speed" questions (e.g. what is the maximum speed of a Harley-Davidson motorbike?) in order to bring the cognitive estimation task into the $21^{\text {st }}$ century. In these questionnaires, cognitive estimation is generally considered to be a uni-dimensional trait, justifying the computation of a total score, where time, duration or speed questions are mixed with questions about length, distance, weight or quantity.

\subsection{The present study}

Overall, there is converging evidence for the role of the cerebellum in time processing of sub-second durations, as well as some evidence for cognitive estimation difficulties in patients with cerebellar lesions for longer durations, possibly related to deficient action-perception coupling. The present study 
compares TK in children treated for medulloblastoma with normative data, and tries to explain the TK difficulties in relation to the proposed roles of the cerebellum in time processing and action-perception coupling.

We discuss our findings using two models of temporal processing as a framework, the dominant internal clock model (Coull, Cheng, \& Meck, 2011a; Droit-Volet, 2013; Gibbon, Church, \& Meck, 1984) and the more recently-proposed state-dependent network model of temporal processing (Buonomano \& Maass, 2009; Goel \& Buonomano, 2014; Karmarkar \& Buonomano, 2007). The first model postulates that estimating duration depends on the accumulation of temporal information in the working memory (Coull, Charras, Donadieu, Droit-Volet, \& Vidal, 2015), whereas the second proposes a qualitative, rather than quantitative, nonlinear and action-dependent coding of time.

\section{Methods}

\subsection{Patients and controls}

The participants were 38 children ( 24 boys, 14 girls) aged 6.1-20.4 years who had been treated for a malignant cerebellar tumor (MCT) and 105 typically-developing children (TDC) (48 boys, 57 girls).

The characteristics of children previously treated for MCT are shown in Table 1. The tumor treatment consisted of surgery, radiotherapy and chemotherapy. The inclusion criteria were having had a malignant cerebellar tumor treated in the Pediatric Oncology Department in the Gustave Roussy Institute (Villejuif, France), being older than 6 years, out of treatment and with no relapse history. The study was approved by the Institutional Review Board (IRB) as a non-interventional study and the parents gave their informed consent for their children's participation. The children came from middleand upper-middle-class backgrounds and were living in urban areas in Metropolitan France and French overseas territories.

The control children, who participated in previous research (Labrell, Mikaeloff, Perdry, \& Dellatolas, 2016), were in general education schools and had experienced no schooling delay. They came from middle- and upper-middle-class backgrounds and were living in an urban area in France.

Informed consent was obtained from all parents in order to conduct this research.

Insert Table 1 about here 
TIME KNOWLEDGE IN MEDULLOBLASTOMA

Table 1 describes the group of 38 children treated for malignant cerebellar tumors. Mean age was 11.6 years. Nineteen children were younger than 11.25 years (which was the age limit for available TK data in the typically-developing children) and 19 were older (11.5 to 20.4 years). There were 24 boys and 14 girls. Age at diagnosis was under 3 years for 13 children, between 3 and 8 years for 13 , and 8 to 18 years for 12 children. The mean time-lapse since diagnosis was 5.6 years and the mean time-lapse since the end of treatment was 4.6 years. One patient was examined at the end of treatment one month after diagnosis; all the other patients were examined at least 5 months after the end of treatments. Thirty-four patients were treated for a medulloblastoma and 4 for an ependymoma. All patients received chemotherapy; all except one underwent surgery; and 35 (92\%) radiotherapy. Eight patients $(21 \%)$ were in special school.

FSIQ scores ranged from 48 to 130 (mean 83); nine patients (24\%) obtained FSIQ<70. The Verbal Comprehension Index (mean=93.6) was significantly higher than the Perceptual Reasoning Index (mean 83.7), the Processing Speed Index (mean 80.4) and the Working Memory Index (mean=81.5), $(p<.001$ in all three cases, paired t-test).

\subsection{Material}

The Time Knowledge Questionnaire (TKQ, Labrell, Mikaeloff, Perdry, \& Dellatolas, 2016) was used (see Appendix A). This questionnaire comprises seven subtests. The first four subtests investigate conventional time knowledge: orientation (OR), sequences (SEQ), time units (TU), and telling the time on a clock (CL), and comprise 5, 3, 4, and 5 questions respectively. The questions about telling the time on a clock use pictures of five analogue clocks with five different positions of the minute and hour hands. Each answer is coded as correct (1 point) or incorrect (0 points), for a total conventional time score from 0 to 17. The fifth subtest, life span (LS), uses four pictures (a baby, a child, a young man, and an old man) illustrating the biological process of ageing at four different stages in development from infancy to old age. The child is asked three questions about the time required to go from one age to the next (i.e. from baby to child, from child to young man, and from young man to old man). Each answer is coded as 0,1 , or 2 points based on the answers of 20 adults: 2 points if the answer is in the adult range, 1 point if it is borderline and 0 points otherwise. The sixth subtest, 
birthday (BIR), comprises three questions (“When is your birthday?”, “How long ago was your birthday?", and “'How long is it to your next birthday?") and correct answers are taken into account in the calculation of the score. For these three questions, the correct answer is available (for each child, date of birth and date of interview are recorded), which makes it possible to use a coding for error. Zero points are given if the child does not know the date of his or her birthday. Otherwise, for both of the last two questions (i.e. time intervals to the previous and next birthdays), 0 points are given for “don't know" and errors exceeding 12 months, and 1, 2, and 3 points are given for errors (i.e. absolute difference between the answer and the correct interval) greater than 3 months, between 3 months and 1 month, and less than 1 month respectively (i.e. total BIR score from 0 to 6 ). The last subtest concerns interview duration (ID). At the end of the interview, the examiner asks the child "For how long have we been here together?" The median duration of the interview is 15 min (inter-quartile range $=14-21$ min, range $=5-42$ ). Zero points are given for "don't know" answers. For all other answers, 0 to 10 points are given according to the absolute difference between the log of the real duration of the interview and the log of the answer (in minutes).

\subsection{Procedure}

The children previously treated for MCT were interviewed from January 2014 to May 2015 at the Gustave Roussy Institute, when they had medical appointments scheduled. The TDC were interviewed individually at their schools, in a quiet room, from February 2015 to June 2015.The participants' answers were fully transcribed.

\subsection{Statistical analysis}

Statistical analysis used SAS version 9 software. To compare TK acquisition between children treated for malignant cerebellar tumor (MCT group) and typically developing children (TDC group) the General Linear Model (GLM) procedure was used, with TK sub scores and TK total score as dependent variables, and age-group (4 levels) and group (2 levels: MCT and TDC) as between-subject factors. Among children older than 10 years, where the age distribution differed between the MCT group (mean age 13.6 years, $\mathrm{SD}=2.5$, range $=10.1-20.4$ ) and the TDC group (mean=10.6 years, 
TIME KNOWLEDGE IN MEDULLOBLASTOMA

$\mathrm{SD}=0.3$, range $=10.1-11.25$ ), TK scores were further compared between groups within this age-group using t-tests and Wilcoxon non-parametric tests. The results of this comparison were retained because the scores were significantly lower in the MCT group, despite the significantly older age of this group. Based on age-group data among the TDC, TK z-scores were calculated for each subject in the MCT group. Only the z-score of the total TK score (TKZ) will be presented. Pearson-correlation coefficients were used for the relationship between IQ and TKZ, and the relationship between these scores and age, age at diagnosis and time-lapse since diagnosis. T-tests were used to ascertain whether subjects in special education institutions obtained lower IQ and TKZ scores.

\section{Results}

\subsection{TK in MCT and TDC groups}

The mean total TK z-score was -2.5 . Twenty children (53\%) obtained TKZ $<-2$ and 27 (71\%) TKS $<-1$. Positive TKZ was obtained by 6 children (16\%), the highest score being 0.81 .

Table 2 compares the time knowledge questionnaire (TKQ) between TDC and children treated for MCT. Performance on all TKQ subtests and TK total score (TKS) were significantly higher in the TDC group than in the MCT group when age was taken into account. Subjects older than 10 years were all aged less than 11.25 years in the TDC group, but between 10 and 20 years in the MCT group. However, despite this age difference between the groups of children older than 10 years, TKS was significantly lower in the MCT group $(\mathrm{p}<.001)$, together with most of the TKQ subtests, in particular telling the time on a clock, long durations (life span and birthday) and temporal sequences.

Insert Table 2 about here

\subsection{TK and neuropsychological factors}

Table 3 shows the factors associated with FSIQ, IQ components and TKZ score, as well as the relationship between TKZ and IQ. Older age and long time-lapse since diagnosis (or long time-lapse since the end of treatments) had a negative impact on FSIQ scores, the processing speed index (PSI), the perceptual reasoning index (PRI), and (for older age) the working memory index (WMI), but not on the verbal comprehension index (VCI) or TKZ. Enrollment in a special educational institution was 
associated with lower IQ scores (except for PRI) and lower TKZ. No significant relationship was observed with young age at diagnosis in this sample. TKZ was only marginally associated with FSIQ $(r=0.30, p=0.07)$ and WMI $(r=0.33, p=0.05)$.

\section{Insert Table 3 about here}

Among subjects with FSIQ scores under $70(n=9)$, between 70 and $90(n=16)$ and higher than 90 $(n=13)$, mean TKZ was -4.7 (4.1), -1.6 (2.0), and -2.1 (2.0) respectively. These three means differed significantly $(F(2,35)=4.3, p=0.02)$ and all differed significantly from $0(p<0.01$ in all three cases $)$. Figure 1 shows the distribution of TKZ according to FSIQ group. Six among the 13 subjects with FSIQ in the normal range ( $>90)$ obtained a total TKZ score under 2.

\section{Discussion}

The present results confirm the lower mean IQ in children treated for malignant cerebellar tumors (MCT), mostly medulloblastoma, related to slow processing speed and low performance on working memory and non-verbal tasks. In our findings the most original results indicate that these children and young adults show considerable difficulties in the acquisition of time knowledge (TK), which cannot be completely explained by low IQ. Among subjects with IQ in the normal range (>90), the mean TK z-score (TKZ) was -2. Correlations were modest between TKZ and FSIQ or Working Memory Index, and low between TKZ and the other IQ components.

The definition of TK adopted, i.e. correct use and representation of time units, logically links TK to numerical skills: the correct use of time units implies the use of numbers. Numerical skills and semantic memory, such as knowledge of the relationships between time units and understanding of the principles of division, contribute to the representation of a given time unit (e.g. knowing that there are 24 hours in a day, 60 minutes in an hour, understanding what one quarter means, etc.). According to a previous study in typically developing children (Labrell, Mikaeloff, Perdry, \& Dellatolas, 2016), investigating the relationship between TK and numerical skills, TK depends on four numerical factors: academic knowledge of numbers and number facts, number line estimation (e.g. correspondence between a number and a distance), verbal working memory, and contextual estimation (e.g. the number 10 is few for "leaves on a tree", but many for "children in a family"). Most of the above four 
TIME KNOWLEDGE IN MEDULLOBLASTOMA

factors could be related to proposed cerebellar cognitive dysfunctions in patients with cerebellar lesions.

Academic knowledge of numbers and number facts could partly depend on sequence learning and automation, and could contribute to explaining difficulties in learning temporal sequences or telling the time on a clock. Sequence learning deficit may be difficult to distinguish from a working memory deficit. In patients with lesions of the cerebellum, some studies have pointed to sequencing difficulties (Leggio et al., 2008), and others to verbal working memory difficulties (Ravizza et al., 2006). Verbal working memory strategies, such as subvocal rehearsal, are likely to be adopted in time reproduction tasks for relatively short intervals (up to a few minutes). The "theory of magnitude" (Walsh, 2003), postulating that the same cognitive system, thought to be located in the inferior parietal cortex, is devoted to common processing mechanisms for the evaluation of time, number and space, and could account for the association of number line estimation with time. In the same vein, Friedman (2000) adopted a spatial coding of time (i.e. distances) to investigate the development of children's knowledge of future events. However, to our knowledge, there is no clear evidence for general "magnitude" deficits in patient with cerebellar pathologies. Life span and duration of the interview are clearly cognitive estimations according to the definition proposed by Shallice and Evans (1978): answers to cognitive estimation questions are based on "general knowledge available to almost all subjects". This contrasts with the reproduction of a given duration after auditory or visual presentation, where a working memory strategy can be applied (e.g. rehearsal). Cognitive estimation may be deficient in patients with lesions of the cerebellum. Executive dysfunction has been described in patients with cerebellar pathologies as a consequence of disconnections between the cerebellum and the frontal cortex (Law et al., 2015). Executive functions are classically attributed to the frontal lobes, as is cognitive estimation. Patients with frontal lesions and planning dysfunctions gave bizarre answers to cognitive estimate questions (Shallice \& Evans, 1978). Furthermore, impaired action-perception coupling has been described in patients with lesions of the cerebellum (Christensen et al., 2014). If we consider that the representation of a given time unit (e.g. one hour) is based on sets of actions that it is possible to perform within this time unit, intact action-perception coupling is required to questions 
about time requiring cognitive estimation. In the study by Hetherington et al. (2000), time estimation was not improved by action

in patients treated for medulloblastoma.

Our results can be interpreted by way of two different models of temporal processing that have been proposed (among others): (i) the very successful internal clock model (Allman et al., 2014; Coull, Cheng, \& Meck, 2011b; Droit-Volet, 2013; Gibbon, Church, \& Meck, 1984), in which time is quantitative (number- and accumulation-based) and linear; (ii) the neural network state model (Buonomano \& Maass, 2009; Goel \& Buonomano, 2014; Karmarkar \& Buonomano, 2007), in which time is qualitative and not linear. The strong correlation between TK and numerical skills, described above, can be considered as an argument in favor of the first model. Nonetheless, the possible relationship of our results with the neural network state model merits some comments.

"Timing in the absence of clocks" has been proposed as a model of time processing by neural networks in the millisecond range (Karmarkar \& Buonomano, 2007). Using computer simulations, the authors conclude that cortical networks are inherently able to tell time as a result of time-dependent changes in network state. In this model, there is no linear metric of time, and a given interval is encoded in the context of preceding events and "temporal objects". According to these authors, the model applies in the millisecond range, but timing in the second range is likely to be more consistent with a linear metric of time. It is important to note, however, that "temporal objects" can be generated not only by neural networks in the millisecond range, but also by behavior in the second, minute, or even longer-range. Traditionally, in humans, during temporal reproduction, temporal discrimination or temporal generalization task, using intervals in the supra-second range, subjects have to be attentive, but they are also often asked to avoid counting (Rattat \& Droit-Volet, 2012), which could interfere with the internal clock model. Indeed, counting is not the only possibility to code a duration of a certain number of seconds, or longer. Coupling the duration of the stimulus with an action could be an alternative strategy. For instance, it is possible to start rehearsing a favorite poem, song or piano sonata at a constant speed at the onset of the stimulus, and code the duration by the stopping-point (the "state") in the poem, the song or the piano sonata. Action-based coding of time of this sort is qualitative, non-numerical and not based on the accumulation of units. Rather it is script-based and 
TIME KNOWLEDGE IN MEDULLOBLASTOMA

event-dependent, which is much closer to the temporal perspective of young children proposed by McCormack (2014).

The above-mentioned dichotomy concerning the concept of time has its philosophical correspondence. In accordance with Aristotle's claim (384-322 B.C., Physics IV, 1941) that time is a number, the dominant theoretical model for time processing is quantitative: regular pulses are produced by an "internal clock" and perception of duration is based on their number. On the other hand, a nonnumerical concept of duration was proposed by Henri Bergson $(1859-1941)$, who thought that numbers are related to space, and not to time. The duration of a piece of music, a "temporal object", could illustrate Bergson's idea. Knowledge or "consciousness" of the number of notes composing, for instance, a piano sonata is not necessary for its correct execution. This is related to the fact that notes in music are not all identical, unlike the pulses of a clock or the time units (Bergson, 1967).

In summary, the correct representation and use of familiar time units depends both on numerical skills and on "intact action-perception coupling". Cerebellar pathologies may lead to numerical deficits related to deficient sequence learning, working memory, cognitive estimation or slow processing speed. If action-perception coupling depends on the integrity of the cerebellum, as reported recently (Christensen et al., 2014; Hetherington et al. 2000), it could add to the explanation of specific timing difficulties in patients with cerebellar lesions, whatever the duration involved. Processing of subsecond timing tasks in the motor system itself suggests action-perception coupling. During processing of timing tasks in the second range, there is evidence that the cerebellum is involved in working memory, and rehearsal can be used to code time intervals by action-perception coupling. For longer durations, there is some evidence that action is less helpful for time perception among patients with lesions of the cerebellum than among healthy subject, although this needs to be confirmed by future studies.

\section{References}

Ait Khelifa-Gallois, N., Puget, S., Longaud, A., Laroussinie, F., Soria, C., Sainte-Rose, C., Dellatolas, G. (2015). Clinical Evidence of the Role of the Cerebellum in the Suppression of Overt Articulatory Movements During Reading. A Study of Reading in Children and Adolescents Treated for Cerebellar Pilocytic Astrocytoma. The Cerebellum, 14, 97-105. 
Allman, M. J., Teki, S., Griffiths, T. D., Meck, W. H. (2014). Properties of the internal clock: firstand second-order principles of subjective time. Annual Review of Psychology, 65, 743-771. http://doi.org/10.1146/annurev-psych-010213-115117

Aristotle. (1941). Physics IV. In R. McKeon (Ed.), The Basic Works of Aristotle. New York: Random House.

Bartlett, F., Kortmann, R., \& Saran, F. (2013). Medulloblastoma. Clinical Oncology (Royal College of Radiologists (Great Britain)), 25(1), 36-45. http://doi.org/10.1016/j.clon.2012.09.008

Baumann, O., Borra, R. J., Bower, J. M., Cullen, K. E., Habas, C., Ivry, R. B., ... Sokolov, A. A. (2015). Consensus paper: the role of the cerebellum in perceptual processes. Cerebellum (London, England), 14(2), 197-220. http://doi.org/10.1007/s12311-014-0627-7

Bergson, H. (1967). Essais sur les Données Immédiates de la Conscience [Time and Free Will: An Essay on the Immediate Data of Consciousness] (Original doctoral dissertation 1889). Paris: Presses Universitaires de France.

Bueti, D., Lasaponara, S., Cercignani, M., Macaluso, E. (2012). Learning about Time: Plastic Changes and Interindividual Brain Differences. Neuron, 75(4), 725-737. http://doi.org/10.1016/j.neuron.2012.07.019

Bullard, S. (2004). The Biber Cognitive Estimation Test*1. Archives of Clinical Neuropsychology, 19(6), 835-846. http://doi.org/10.1016/j.acn.2003.12.002

Buonomano, D. V., \& Maass, W. (2009). State-dependent computations: spatiotemporal processing in cortical networks. Nature Reviews Neuroscience, 10(2), 113-125. http://doi.org/10.1038/nrn2558

Chevignard, M., Câmara-Costa, H., Doz, F., Dellatolas, G. (2016). Core Deficits and Quality of Survival after childhood medulloblastoma: a review. Neuro-Oncology Practice. doi:10.1093/nop/npw013

Christensen, A., Giese, M. A., Sultan, F., Mueller, O. M., Goericke, S. L., Ilg, W., Timmann, D. (2014). An intact action-perception coupling depends on the integrity of the cerebellum. The Journal of Neuroscience: The Official Journal of the Society for Neuroscience, 34(19), 67076716. http://doi.org/10.1523/JNEUROSCI.3276-13.2014

Coull, J. T., Charras, P., Donadieu, M., Droit-Volet, S.,Vidal, F. (2015). SMA Selectively Codes the Active Accumulation of Temporal, Not Spatial, Magnitude. Journal of Cognitive Neuroscience, 27(11), 2281-2298. http://doi.org/10.1162/jocn_a_00854

Coull, J. T., Cheng, R.-K., \& Meck, W. H. (2011a). Neuroanatomical and Neurochemical Substrates of Timing. Neuropsychopharmacology, 36(1), 3-25. http://doi.org/10.1038/npp.2010.113

Coull, J. T., Cheng, R.-K., \& Meck, W. H. (2011b). Neuroanatomical and Neurochemical Substrates of Timing. Neuropsychopharmacology, 36(1), 3-25. http://doi.org/10.1038/npp.2010.113

De Zeeuw, C. I., \& Ten Brinke, M. M. (2015). Motor Learning and the Cerebellum. Cold Spring Harbor Perspectives in Biology, 7(9), a021683. http://doi.org/10.1101/cshperspect.a021683

Droit-Volet, S. (2013). Time perception in children: A neurodevelopmental approach. Neuropsychologia, 51(2), 220-234. http://doi.org/10.1016/j.neuropsychologia.2012.09.023

Friedman, W. J. (1986). The Development of Children's Knowledge of Temporal Structure. Child Development, 57(6), 1386. http://doi.org/10.2307/1130418 
Friedman, W. J. (2000). The Development of Children's Knowledge of the Times of Future Events. Child Development, 71(4), 913-932. http://doi.org/10.1111/1467-8624.00199

Gibbon, J., Church, R. M., \& Meck, W. H. (1984). Scalar timing in memory. Annals of the New York Academy of Sciences, 423, 52-77.

Goel, A., \& Buonomano, D. V. (2014). Timing as an intrinsic property of neural networks: evidence from in vivo and in vitro experiments. Philosophical Transactions of the Royal Society B: Biological Sciences, 369(1637), 20120460-20120460. http://doi.org/10.1098/rstb.2012.0460

Gooch, C. M., Wiener, M., Wencil, E. B., Coslett, H. B. (2010). Interval timing disruptions in subjects with cerebellar lesions. Neuropsychologia, 48(4), 1022-1031. http://doi.org/10.1016/j.neuropsychologia.2009.11.028

Grill, J., Renaux, V. K., Bulteau, C., Viguier, D., Levy-Piebois, C., Sainte-Rose, C., ... Kalifa, C. (1999). Long-term intellectual outcome in children with posterior fossa tumors according to radiation doses and volumes. International Journal of Radiation Oncology, Biology, Physics, $45(1), 137-145$.

Grill, J., Viguier, D., Kieffer, V., Bulteau, C., Sainte-Rose, C., Hartmann, O., ... Dellatolas, G. (2004). Critical risk factors for intellectual impairment in children with posterior fossa tumors: the role of cerebellar damage. Journal of Neurosurgery, 101(2 Suppl), 152-158. http://doi.org/10.3171/ped.2004.101.2.0152

Harrington, D. L. (2003). Does the representation of time depend on the cerebellum?: Effect of cerebellar stroke. Brain, 127(3), 561-574. http://doi.org/10.1093/brain/awh065

Hayashi, M. J., Kantele, M., Walsh, V., Carlson, S., Kanai, R. (2014). Dissociable neuroanatomical correlates of subsecond and suprasecond time perception. Journal of Cognitive Neuroscience, 26(8), 1685-1693. http://doi.org/10.1162/jocn_a_00580

Hetherington, R., Dennis, M., \& Spiegler, B. (2000). Perception and estimation of time in long-term survivors of childhood posterior fossa tumors. Journal of the International Neuropsychological Society: JINS, 6(6), 682-692.

Ivry, R. B., \& Keele, S. W. (1989). Timing functions of the cerebellum. Journal of Cognitive Neuroscience, 1(2), 136-152. http://doi.org/10.1162/jocn.1989.1.2.136

Janeslätt, G., Granlund, M., Kottorp, A., Almqvist, L. (2010). Patterns of Time Processing Ability in Children with and without Developmental Disabilities. Journal of Applied Research in Intellectual Disabilities, 23(3), 250-262. http://doi.org/10.1111/j.1468-3148.2009.00528.x

Karmarkar, U. R., \& Buonomano, D. V. (2007). Timing in the Absence of Clocks: Encoding Time in Neural Network States. Neuron, 53(3), 427-438. http://doi.org/10.1016/j.neuron.2007.01.006

Keren-Happuch, E., Chen, S.-H. A., Ho, M.-H. R., Desmond, J. E. (2014). A meta-analysis of cerebellar contributions to higher cognition from PET and fMRI studies. Human Brain Mapping, 35(2), 593-615. http://doi.org/10.1002/hbm.22194

Koustenis, E., Hernáiz Driever, P., de Sonneville, L., Rueckriegel, S. M. (2016). Executive function deficits in pediatric cerebellar tumor survivors. European Journal of Paediatric Neurology, 20(1), 25-37. http://doi.org/10.1016/j.ejpn.2015.11.001

Koziol, L. F., Budding, D., Andreasen, N., D’Arrigo, S., Bulgheroni, S., Imamizu, H., ... Yamazaki, T. (2014). Consensus paper: the cerebellum's role in movement and cognition. Cerebellum (London, England), 13(1), 151-177. http://doi.org/10.1007/s12311-013-0511-x 
Labrell, F., Kieffer, V., Grill, J., Dellatolas, G. (2014). Conceptions of time in children treated for malignant cerebellar tumours. Brain Injury, 28(10), 1334-1341. http://doi.org/10.3109/02699052.2014.910699

Labrell, F., Mikaeloff, Y., Perdry, H., Dellatolas, G. (2016). Time knowledge acquisition in children aged 6 to 11 years and its relationship with numerical skills. Journal of Experimental Child Psychology, 143, 1-13. http://doi.org/10.1016/j.jecp.2015.10.005

Law, N., Smith, M. L., Greenberg, M., Bouffet, E., Taylor, M. D., Laughlin, S., ... Mabbott, D. (2015). Executive function in paediatric medulloblastoma: The role of cerebrocerebellar connections. Journal of Neuropsychology. http://doi.org/10.1111/jnp.12082

Leggio, M. G., Tedesco, A. M., Chiricozzi, F. R., Clausi, S., Orsini, A., Molinari, M. (2008). Cognitive sequencing impairment in patients with focal or atrophic cerebellar damage. Brain: A Journal of Neurology, 131(Pt 5), 1332-1343. http://doi.org/10.1093/brain/awn040

Mabbott, D. J., Penkman, L., Witol, A., Strother, D., Bouffet, E. (2008a). Core neurocognitive functions in children treated for posterior fossa tumors. Neuropsychology, 22(2), 159-168. http://doi.org/10.1037/0894-4105.22.2.159

Mabbott, D. J., Penkman, L., Witol, A., Strother, D., Bouffet, E. (2008b). Core neurocognitive functions in children treated for posterior fossa tumors. Neuropsychology, 22(2), 159-168. http://doi.org/10.1037/0894-4105.22.2.159

MacPherson, S. E., Wagner, G. P., Murphy, P., Bozzali, M., Cipolotti, L., Shallice, T. (2014). Bringing the Cognitive Estimation Task into the 21st Century: Normative Data on Two New Parallel Forms. PLoS ONE, 9(3), e92554. http://doi.org/10.1371/journal.pone.0092554

Marvel, C. L., \& Desmond, J. E. (2010). Functional Topography of the Cerebellum in Verbal Working Memory. Neuropsychology Review, 20(3), 271-279. http://doi.org/10.1007/s11065-010-91377

McCormack, T. (2014). Three types of temporal perspective: characterizing developmental changes in temporal thought: Development of temporal thought. Annals of the New York Academy of Sciences, 1326(1), 82-89. http://doi.org/10.1111/nyas.12504

Mulhern, R. K., Reddick, W. E., Palmer, S. L., Glass, J. O., Elkin, T. D., Kun, L. E., ... Gajjar, A. (1999). Neurocognitive deficits in medulloblastoma survivors and white matter loss. Annals of Neurology, 46(6), 834-841.

Nyberg, L., Kim, A. S. N., Habib, R., Levine, B., Tulving, E. (2010). Consciousness of subjective time in the brain. Proceedings of the National Academy of Sciences, 107(51), 22356-22359. http://doi.org/10.1073/pnas.1016823108

Palmer, S. L., Armstrong, C., Onar-Thomas, A., Wu, S., Wallace, D., Bonner, M. J., ... Gajjar, A. (2013). Processing Speed, Attention, and Working Memory After Treatment for Medulloblastoma: An International, Prospective, and Longitudinal Study. Journal of Clinical Oncology, 31, 3494-3500.

Palmer, S. L., Goloubeva, O., Reddick, W. E., Glass, J. O., Gajjar, A., Kun, L., ... Mulhern, R. K. (2001). Patterns of intellectual development among survivors of pediatric medulloblastoma: a longitudinal analysis. Journal of Clinical Oncology: Official Journal of the American Society of Clinical Oncology, 19(8), 2302-2308.

Provasi, J., Doyère, V., Zélanti, P. S., Kieffer, V., Perdry, H., El Massioui, N., ... Droit-Volet, S. (2014). Disrupted sensorimotor synchronization, but intact rhythm discrimination, in children treated for a cerebellar medulloblastoma. Research in Developmental Disabilities, 35(9), 2053-2068. http://doi.org/10.1016/j.ridd.2014.04.024 
TIME KNOWLEDGE IN MEDULLOBLASTOMA

Puget, S., Boddaert, N., Viguier, D., Kieffer, V., Bulteau, C., Garnett, M., ... Grill, J. (2009). Injuries to inferior vermis and dentate nuclei predict poor neurological and neuropsychological outcome in children with malignant posterior fossa tumors. Cancer, 115(6), 1338-1347. http://doi.org/10.1002/cncr.24150

Rahmati, N., Owens, C. B., Bosman, L. W. J., Spanke, J. K., Lindeman, S., Gong, W., ... De Zeeuw, C. I. (2014). Cerebellar potentiation and learning a whisker-based object localization task with a time response window. The Journal of Neuroscience: The Official Journal of the Society for Neuroscience, 34(5), 1949-1962. http://doi.org/10.1523/JNEUROSCI.2966-13.2014

Ramnani, N. (2014). Automatic and Controlled Processing in the Corticocerebellar System. In Progress in Brain Research (Vol. 210, pp. 255-285). Elsevier.

Rao, S. M., Harrington, D. L., Haaland, K. Y., Bobholz, J. A., Cox, R. W., Binder, J. R. (1997). Distributed neural systems underlying the timing of movements. The Journal of Neuroscience: The Official Journal of the Society for Neuroscience, 17(14), 5528-5535.

Rattat, A.-C., \& Droit-Volet, S. (2012). What is the best and easiest method of preventing counting in different temporal tasks? Behavior Research Methods, 44(1), 67-80. http://doi.org/10.3758/s13428-011-0135-3

Ravizza, S. M., McCormick, C. A., Schlerf, J. E., Justus, T., Ivry, R. B., Fiez, J. A. (2006). Cerebellar damage produces selective deficits in verbal working memory. Brain: A Journal of Neurology, 129(Pt 2), 306-320. http://doi.org/10.1093/brain/awh685

Schmahmann, J. D., \& Sherman, J. C. (1998). The cerebellar cognitive affective syndrome. Brain: A Journal of Neurology, 121 ( Pt 4), 561-579.

Shallice, T., \& Evans, M. E. (1978). The involvement of the frontal lobes in cognitive estimation. Cortex; a Journal Devoted to the Study of the Nervous System and Behavior, 14(2), 294-303.

Szpunar, K. K., Watson, J. M., \& McDermott, K. B. (2007). Neural substrates of envisioning the future. Proceedings of the National Academy of Sciences, 104(2), 642-647. http://doi.org/10.1073/pnas.0610082104

Tulving, E. (2002). Episodic memory: from mind to brain. Annual Review of Psychology, 53, 1-25. http://doi.org/10.1146/annurev.psych.53.100901.135114

Walsh, V. (2003). A theory of magnitude: common cortical metrics of time, space and quantity. Trends in Cognitive Sciences, 7(11), 483-488.

Wiener, M., Turkeltaub, P., \& Coslett, H. B. (2010). The image of time: a voxel-wise meta-analysis. NeuroImage, 49(2), 1728-1740. http://doi.org/10.1016/j.neuroimage.2009.09.064

Wolfe, K. R., Madan-Swain, A., \& Kana, R. K. (2012). Executive Dysfunction in Pediatric Posterior Fossa Tumor Survivors: A Systematic Literature Review of Neurocognitive Deficits and Interventions. Developmental Neuropsychology, 37(2), 153-175. http://doi.org/10.1080/87565641.2011.632462 


\section{Appendix A: The Time Knowledge Questionnaire (TKQ)}

Orientation (OR): (1) What day is it today? (2) What time is it**? (3) In what month are we? (4) In what year are we? (5) In what season are we?

Sequences (SEQ): (1) What month comes after March? (2) Can you tell me the months in the year in order? (3) Can you tell me the seasons in the year in order?

Time units (TU): (1) Is a minute shorter or longer than a second? (2) Is a week longer or shorter than a month? (3) Is a month shorter or longer than a year? (4) How many hours are there in one day, from one day in the morning to the next day in the morning?

Telling the time on a clock (CL) (six images of a clock): (1) Show me 2 o'clock. (2) Show me 10 to 3. (3) Show me a quarter past 8. (4) Show me 10 past 11. (5) Look at this clock. How many minutes is it to2 o'clock?

Life span (LS) (four pictures: baby, child, young man, and old man): How long does it take: (1) for a baby (here) to become a child (here)? (2) for a child (here) to become a young man (here)? (3) for a young man to become an old man?

Birthday (BIR): (1) * How old are you? (2) * When is your birthday? (3) How long ago was your birthday? (4) How long is it to your next birthday?

Interview duration (ID): (1) For how long have we been here together?

* Questions not considered in the calculation of sub scores and total score.

**Considered as correct if the child's answer is in the same half day (if it is 10 o'clock and the answer is "it is 8 o'clock" or "it is midday," the child's answer is considered as correct, but if the child's answer is " it is 4 o'clock in the afternoon", it is considered as incorrect). 
TIME KNOWLEDGE IN MEDULLOBLASTOMA

\section{Table captions}

Table 1. Characteristics of children with MCT

Table 2. Sub scores on time knowledge questionnaire (TKQ) in typically developing children (TDC) and in children treated for malignant cerebellar tumor (MCT)

Table 3. Factors associated with FSIQ, IQ components and TKZ score, and correlations between TKZ and IQ components 
TIME KNOWLEDGE IN MEDULLOBLASTOMA

Table 1

Characteristics of children with MCT

\begin{tabular}{|c|c|}
\hline $\mathbf{N}$ & 38 \\
\hline Age: m (SD) [range] (years) & $11.6(3.7)[6.1-20.4]$ \\
\hline Age at diagnosis & $6.0(4.4)[0.1-18.0]$ \\
\hline Time-lapse since diagnosis & $5.6(4.4)[0.1-14.9]$ \\
\hline Sex (boys): N (\%) & $24(63)$ \\
\hline \multicolumn{2}{|l|}{ Tumor } \\
\hline Medulloblastoma & $34(90)$ \\
\hline Ependymoma & $4(10)$ \\
\hline \multicolumn{2}{|l|}{ Treatment } \\
\hline Surgery & $37(97)$ \\
\hline Radiotherapy & $35(92)$ \\
\hline Chemotherapy & $38(100)$ \\
\hline \multicolumn{2}{|l|}{ School } \\
\hline Special institution & $8(21)$ \\
\hline \multicolumn{2}{|c|}{ Wechsler scales: m (SD) [range] } \\
\hline Full scale IQ & $83.0(17.9)[48-130]$ \\
\hline VCI & $93.6(15.8)[63-122]$ \\
\hline PRI & $83.7(15.5)[54-126]$ \\
\hline PSI & $80.4(18.0)[50-118]$ \\
\hline WMI & $81.5(14.5)[50-112]$ \\
\hline
\end{tabular}


TIME KNOWLEDGE IN MEDULLOBLASTOMA

Table 2

Sub scores on time knowledge questionnaire (TKQ) in typically developing children (TDC) and in children treated for malignant cerebellar tumor (MCT)

\begin{tabular}{|c|c|c|c|c|c|c|c|c|c|c|c|}
\hline \multirow[b]{2}{*}{ Age group: } & \multirow[b]{2}{*}{ Max } & \multicolumn{5}{|c|}{ Typically developing children (TDC) } & \multicolumn{4}{|c|}{ Malignant Cerebellar Tumors (MCT) } & \multirow[b]{2}{*}{ Total } \\
\hline & & $\begin{array}{l}6-7 \\
(17)\end{array}$ & $\begin{array}{c}7 \\
\text { (19) }\end{array}$ & $\begin{array}{l}8-9 \\
(50)\end{array}$ & $\begin{array}{l}>10 * \\
(19)\end{array}$ & $\begin{array}{l}\text { Total } \\
\text { (105) }\end{array}$ & $\begin{array}{l}6-7 \\
(5)\end{array}$ & $\begin{array}{c}7 \\
(3)\end{array}$ & $\begin{array}{l}\text { 8-9 } \\
(4)\end{array}$ & $\begin{array}{l}>10 * \\
(26)\end{array}$ & \\
\hline Orientation (OR) & 5 & $3.6(1.2)$ & $4.7(0.6)$ & $4.9(0.4)$ & $5.0(0.0)$ & $4.6(0.8)$ & $2.8(1.9)$ & $4.3(0.6)$ & $4.5(0.6)$ & $4.7(0.6)$ & $4.3(1.1)$ \\
\hline Sequences (SEQ) & 3 & $0.9(0.8)$ & $2.1(1.0)$ & $2.4(0.7)$ & $2.9(0.3)$ & $2.2(0.9)$ & $0.6(0.9)$ & $1.0(1.0)$ & $1.5(0.6)$ & $2.2(0.9)$ & $1.8(1.0)$ \\
\hline Time units (TU) & 4 & $1.7(0.9)$ & $3.1(0.8)$ & $3.8(0.6)$ & $3.9(0.2)$ & $3.3(1.0)$ & $1.2(0.4)$ & $2.0(2.0)$ & $2.5(1.3)$ & $3.7(0.6)$ & $3.1(1.3)$ \\
\hline Clock (CL) & 5 & $2.1(1.6)$ & $3.7(1.0)$ & $4.0(0.9)$ & $4.9(0.3)$ & $3.8(1.3)$ & $1.8(1.6)$ & $2.3(2.1)$ & $2.5(1.9)$ & $4.0(0.9)$ & $3.4(1.5)$ \\
\hline Life Span (LS) & 6 & $2.1(2.0)$ & $3.7(2.2)$ & $4.7(1.5)$ & $5.2(0.8)$ & $4.2(1.9)$ & $0.8(0.8)$ & $2.0(2.7)$ & $1.3(1.0)$ & $4.0(1.4)$ & $3.2(1.9)$ \\
\hline Birthday (BIR) & 6 & $1.6(2.0)$ & $3.8(2.0)$ & $4.9(1.3)$ & $5.5(0.7)$ & $4.3(2.0)$ & $1.8(2.0)$ & $1.0(1.7)$ & $2.8(2.5)$ & $3.9(2.0)$ & $3.2(2.2)$ \\
\hline Total Score (TKS) & 39 & $15.9(6.0)$ & $26.9(7.0)$ & $32.3(3.7)$ & $36.3(2.1)$ & $29.4(8.1)$ & $10.2(6.0)$ & $17.3(12.3)$ & $18.5(6.4)$ & $30.5(6.7)$ & $25.4(10.2)$ \\
\hline
\end{tabular}

ANOVA: Age group effect, $p<.001$ for TKS and all subtests. Group effect (TDC vs. MCT), $p<.01$ for OR and ID, $p<.001$ for TKS and all other subtests. Group by age group interaction NS $(p \geq .05)$

*age group >10: TDC group: all 19 children were aged between 10.1 and 11.25. MCT group: 7 of the 26 children (27\%) were aged between 10.1 and 11.25 years and 19 (73\%) between 11.6 and 20.4 years. However, all means were higher among the TDC than among children with MCT. A comparison (t-test or non-parametric Wilcoxon test gave similar results) showed significant differences: $p<.001$ for TKS and CL, $p<.01$ for SEQ, LS, BIR, $p<.05$ for OR (Wilcoxon), but no significant difference for TU and ID. 
TIME KNOWLEDGE IN MEDULLOBLASTOMA

\section{Table 3}

Factors associated with FSIQ, IQ components and TKZ score, and correlations between TKZ and IQ components

\begin{tabular}{lcccccc}
\hline & FSIQ & VCI & PRI & PSI & WMI & TKZ \\
\cline { 2 - 7 } Age & $-0.48^{* *}$ & -0.13 & $-0.34^{*}$ & $-0.46^{* *}$ & $-0.34^{*}$ & 0.03 \\
Age at diagnosis & -0.07 & 0.04 & 0.07 & 0.13 & -0.14 & 0.20 \\
Time-lapse since diagnosis & $-0.36^{*}$ & -0.13 & $-0.33^{*}$ & $-0.47^{* *}$ & -0.13 & -0.17 \\
TKZ & 0.30 & 0.26 & 0.22 & 0.07 & $0.33^{*}$ & - \\
\hline
\end{tabular}

FSIQ: Full Scale Intellectual Quotient; VCI: Verbal Comprehension Index; PRI: Perceptual Reasoning Index; PSI: Processing Speed Index; WMI: Working Memory Index; TKZ: Time Knowledge Z score. 
TIME KNOWLEDGE IN MEDULLOBLASTOMA

\section{Figures Caption}

Figure 1. Distribution of TKZ according to FSIQ group.

1

2

3

4

5

6

7

8

9

10

11

12

13

14

15

16

17

18

19

20

21

22

23

24

25

26

27

28

29

30

31

32

33

34

35

36

37

38

39

40

41

42

43

44

45

46

47

48

49

50

51

52

53

54

55

56

57

58

59

60 
TIME KNOWLEDGE IN MEDULLOBLASTOMA

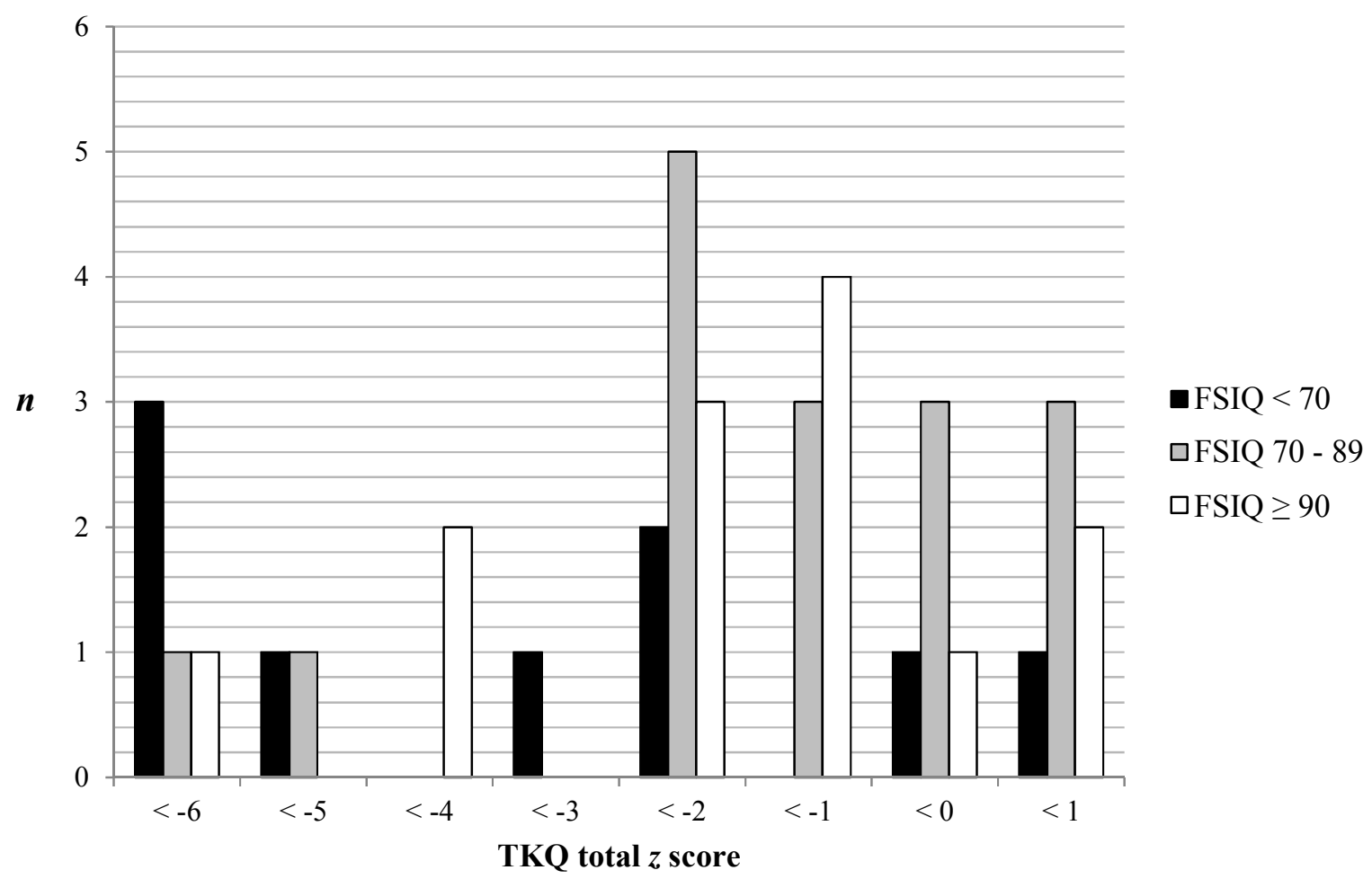

Figure 1: Distribution of TKZ according to FSIQ group. 